\title{
Mafhum an-Nahyi Baina al-Balaghiyyin Wa al-Ushuliyyin
}

\author{
Bambang \\ Universitas Muhammadiyah Sumatra Barat (UMSB) \\ bambangmindai@yahoo.co.id \\ Hazuar \\ Sekolah Tinggi Agama Islam Negeri (STAIN) Curup \\ azazwae@gmail.com
}

\begin{abstract}
ملخص
البحث عن النهي من المباحث التي اشتغل بها البلاغيون والأصوليون لأجل أغراض تختلف بينهما وفقا بموضوع البحث بين هذين العلمين. كان البلاغيون يقومون أمام النصوص العربية لغرض استخراج الأحكام اللغوية المتضمنة من خلال تلك النصوص، وهذه الأحكام إما أن تكون تتعلق بالمعنى أو اللفظ أو طريقة تأدية الكلام. فالبحوث عن النهي عندهم لا تخلو من هذه الدافعية اللغوية، فيبحثون من خلال النصوص التي تتضمن صيغ النهي عن معانيها اللغوية كالنهي بمعنى الحقيقي وهو طلب امتناع الفعل من الأعلى إلى الأدنى أو معنى غير الحقيقي وهي معاني التي تخرج من هذه المعاني الأصلية التي تعرف من خلال سياق الكلام وقرائن الأحوال. أما الأصوليون فأغراضهم البحوث عن النهي لغرض تهري استخراج الأحكام الشرعية الكلية التي تتفرع منها الأحكام الشرعية الجزئية، فيستخرجون

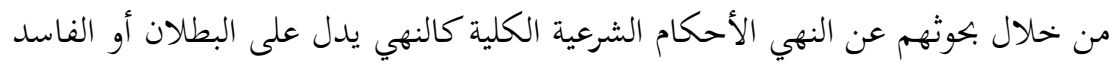
إذا كان النهي مطلقا عن القرائن الدالة على أن النهي عنه قبيح لعينه أو لغيره، أو لا يدل على البطلان إذا كان النهي عن العمل راجعا إلى وصف بجاور له، ينفك عنه، غير لازم له وذلك كالنهي عن الصالة في الأرض المغصوبة. فهذه كلها من أنواع الأحكام الشرعية الكلية. الكلمات المفتوحة: النهي، البلاغيين، الأصوليين
\end{abstract}




\begin{abstract}
The Nahi study is one of the studies of concern among scholars Balaghah and Ushul fiqih. The source of the difference between the two branches of the discipline refers to the object of study and the goal to be achieved between the two. The object of Balajiah scholars' study is related to the meaning of language contained in the uslub nabi and how the use of uslub nabi in the language of good communication and effective so that there is no communication error between the speaker and the other person. The result of their discussion is that the uslub nabi contains two meanings namely the essential meaning and metaphor. The intrinsic meaning is the prohibition arises from a speaker whose position is superior to the opposite speaker, while the meaning of metaphoric is contrary to the intrinsic meaning, and this change of meaning can be analyzed through the context of the use of language. As for ulama ushul fiqih, their study of nabi is not to explore the meaning of the language contained in uslub nahi, but focused to explore the content of islamic law contained in uslub nabi. The conclusion of their study that nahi sometimes implicate the law cancellation of something that is prohibited either in the form of acts or the other, and sometimes also nabi not implicate cancellation of what is prohibited.
\end{abstract}

Keyword: An-Nahy, Balaghiyyin, Ushuliyyin

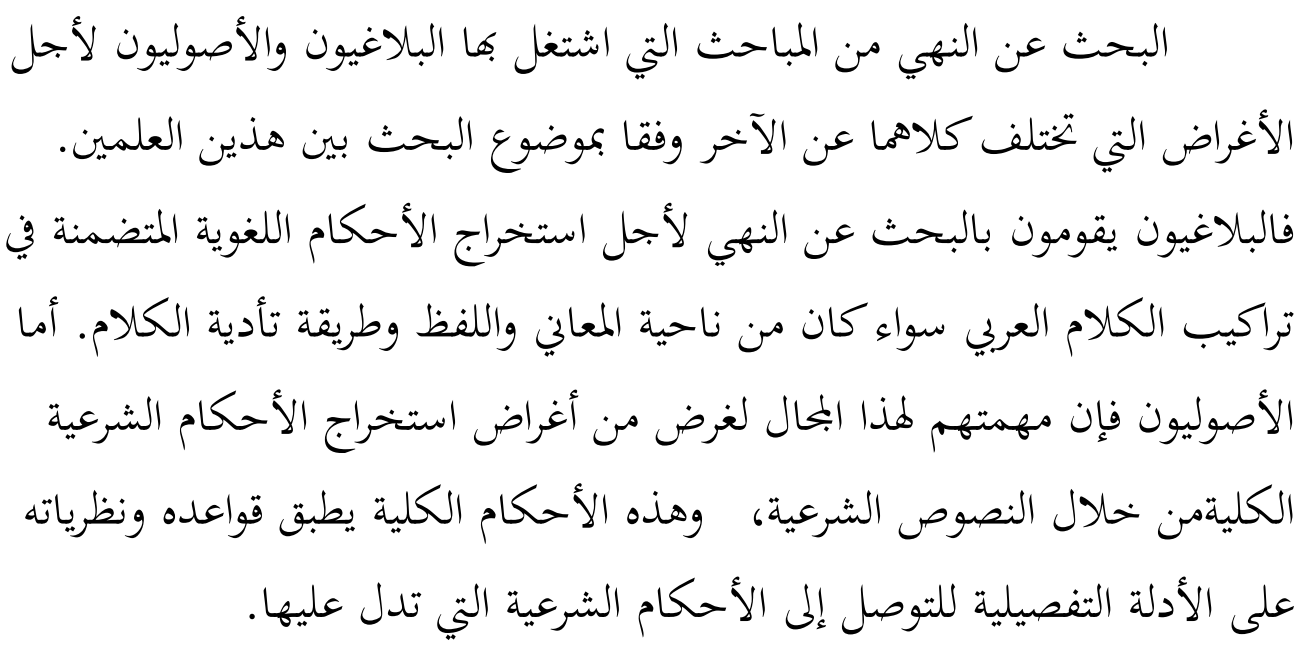


إن نشأة علم البلاغة - كعلم من علوم العربية- ترتبط وثيقا ببحوث

الإعجاز القرآي. ' وأول من اتختص بهذا العلم هو أبو عبيدة معمر بن مثنى ( 213 هـ) الذي ألف كتابه "بحاز القرآن". وهو أول من بحث عن البلاغة ثم أتبعه العلماء بعده مثل الجاحظ (ت. 255هـ) الذي ألف كتابه البيان والتبيين. وجاء بعد هذه الفترة محاولة التطوير من قبل العلماء الذي بحث البلاغة من جوانب أخرى كابن المعتز (296 هـ) الذي يحلل الأسلوب العربية ويصنفه في كتابه البديع وتعد عمليته من بعده بمباحث علم البديع. ويليه قدامة بن جعفر (337 هـ) الذي أسس قواعد نقد الشعر في كتابه "نقد الشعر"، وجاء من بعده أبو هلال العسكري ( 395 هـ) الذي أسس قواعد الباغة التي تتعلق بالفصاحة والإيجاز والإطناب في كتابه الصناعتين.

وقد بلغت المباحث عن إعجازية القرآن إلى ذروتا في فاية هذه الفترة على يد عبد القاهر الجرجاني ( 474 هـ) الذي بحث إعجازية القرآن من ناحية نظمه وهو يبحث نصوص القرآن التي لها آثار فسيكولوجي والذوق الجمالي ويصنف مباحثه في كتابه دلائل الإعجاز وأسرار البلاغة. وتعد مباحثه في كتابه الأول من مباحث علم المعاني وكتابه الثاني من العلم البيان. وتعد عبد القاهر واضع علم المعاني والبيان من أجل جهده في هذين العلمين وكذالك تعد ابن المعتز واضع علم

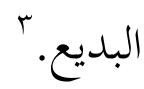

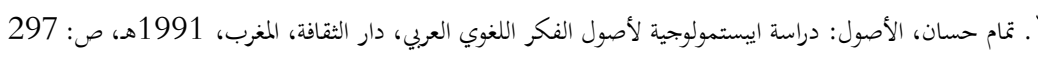

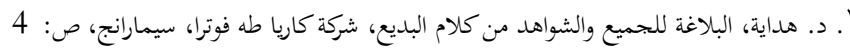


أما علم أصول الفقه فينشأ في القرن الثاني الهجري، لأنه في القرن الأول

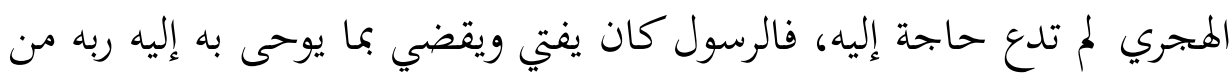
القرآن، وبما يلهم به من السنن. وبما يؤديه إليه إجتهاده الفطري من غير حاجة إلى

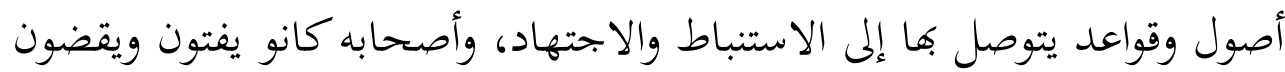

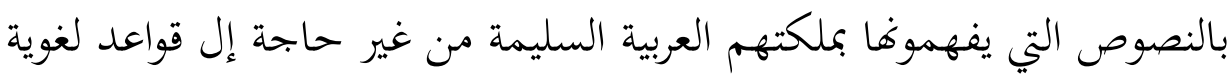

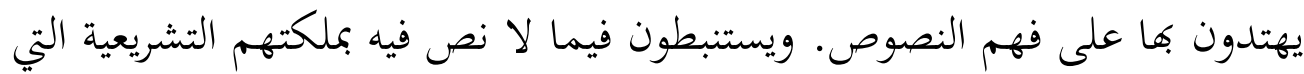
ركزت في نفوسهم من صحبتهم الرسول ووقوفهم على اسباب نزول الآيات وورود الأحاديث وفهمهم مقاصد الشارع ومبادئ التشريع.

ومع اتساع الفتوح الإسلامية واختلط العربية بغيرهم وتشافحوا وتكاتبوا

ودخل في العربية كثير من المفردات والأساليب غير العبية ولم تبق الملكة اللسانية

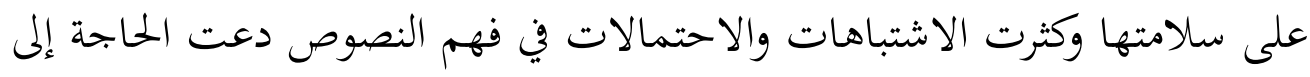
وضع ضوابط وقواعد لغوية يقتدر بها على فهم النصوص كما يفهمها العربي الذي وردت النصوص بلغته.

وأول من دون من قواعد هذا العلم وبحوثه بحموعة مستقلة مرتبة مؤيدا كل

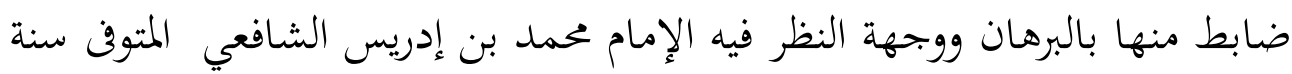

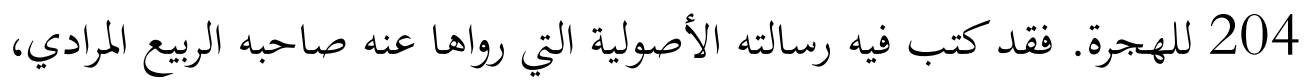

$$
\text { ". "المصدر الوهاب الخلاف، علم أصول الفقه، دار العلم، 1978، ص: } 16
$$




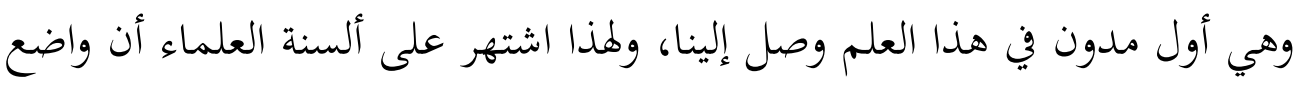

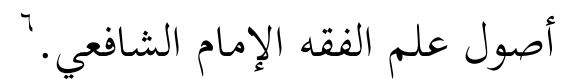

وهذه الدراسة ستبحث عن مباحث النهي عند البلاغيين والأصوليين حتى تتضح من خلال هذا البحث مدى وجهة الاتفاق والاختلاف بينهما.

النهي عند البلاغيين

علم البلاغة هو فرع من فروع علوم اللغة العربية، وأما موضوع بحثه فهو

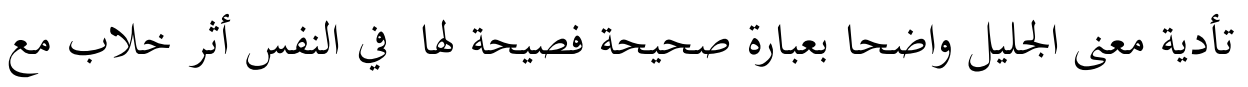

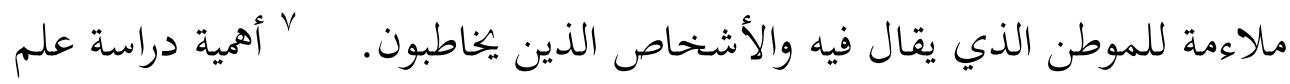
البلاغة لدراسة البلاغة أهمية كبيرة في حياتنا وفي بحالات متعددة لإدة ومتنوعة في الكون، ومن أهمّ فوائد دراسة علم البلاغة: تساعد البلاغة على معرفة معاني القرآن،

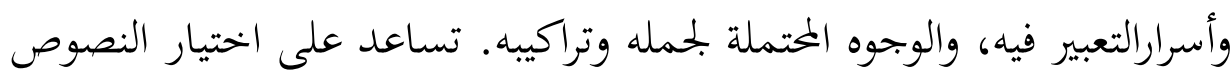
البليغة من الشعر والنثر وغيرها من أضرب الكالام. تنمي القدرة على تمييز الكلام

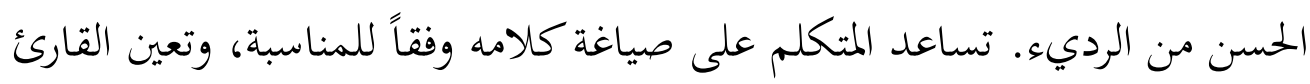

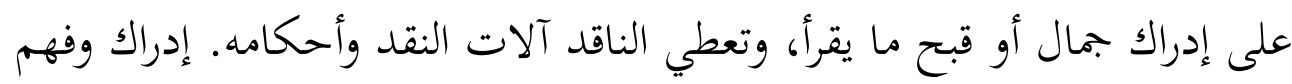
الجمل التي يتم قرائتها. القدرة على إنتقاد النصوص الأدبية بطريقةٍ صحيحةٍ وخاليةٍ

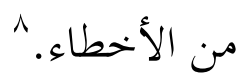

•

“

http://mawdoo3.com .^ 
وقد انقسم هذا العلم إلى تقسيم ثلاث وهو علم المعاني والبيان والبديع. 9 ولكل هذا التقسيم له بحوث خاص به، وكان موضوع علم المعاني هو اللفظ العربي من حيث إفادة معاني الثواني التي هي الأغراض المقصودة للمتكلم من جعل الكلام مشتملا على تلك اللطائف والخصوصيات التي بها يطابق اقتضاء الحال. ومن فوائد هذا العلم هي معرفة إعجاز القرآن الكريم والوقوف على أسرار البلاغة وفصاحة اللغة العربية سواء كان في منثور كلامهم أو منظومه. '1 ومن الأمور التي اشتغلت بها رجال المعاني هي كلامهم عن تقسيم الكالام وهو ينقسم إلى الخبر والإنشأ. والخبر عندهم هو ما يتحقق في الخارج بدون النطق به مثل : العلم نافع. 'ل" والإنشأ هو ما لا يكصل مضمونه ولا يتحقق إلا إذا تلفظت به، فطلب الفعل في "|قرأ" وطلب الكف في " لا تقرأ " كل ذلك ما حصل إلا بنفس الصيغ المتلفظ بها. وينقسم الإنشأ إلى نوعين طلبي وغير طلبي. فالإنشأ غير طلبي هو ما لا يستدعي مطلوبا غير حاصل وقت الطلب ويكون بصيغ المدح والذم وصيغ العقود والقسم والتعجب والرجاء. وهذا نوع الإنشأ لا يبحثه علماء البالاغة لأن أكثر صيغه في الأصل اخبار نقلت إلى الإنشأ. وإنما المبحوث عنه في علم المعاني هو الإنشأ الطلبي لما يمتاز به من لطائف بلاغية. 
والإنشأ الطلبي هو الذي يستدعي مطلوبا غير حاصل في اعتقاد المتكلم

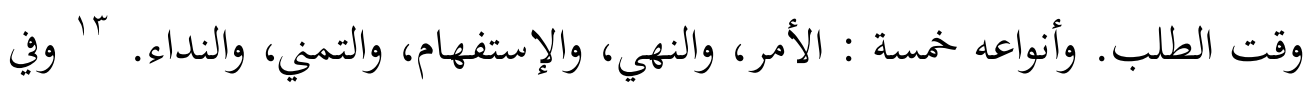

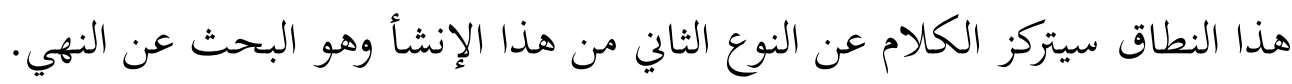

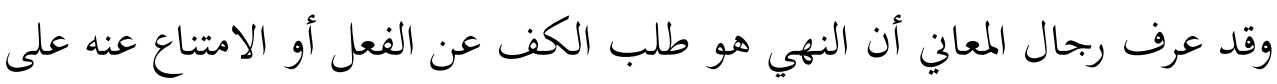

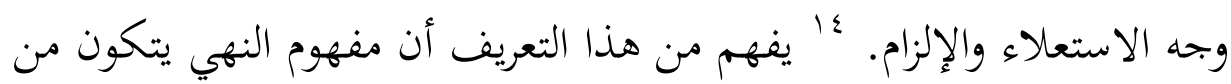
العناصر التالية : الأول: أن النهي هو عبارة عن طلب الكف عن عن الفعل أو الامتناع

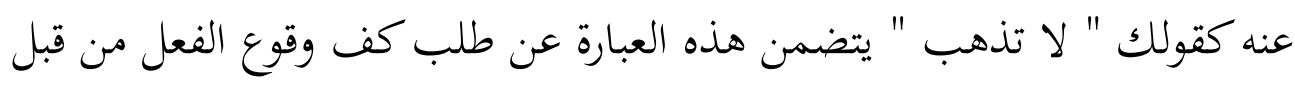

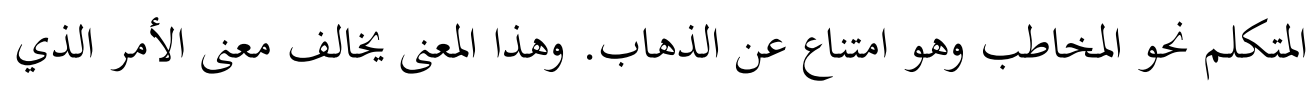

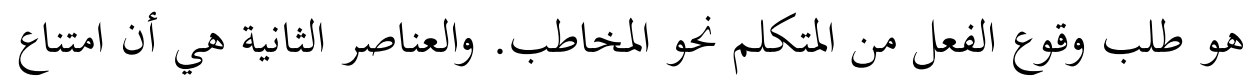
الفعل في عبارة النهي هو امتناع استعلائي وهو أنه يصدر من الأعلى إلى الأدنى. وإذا وقع النهي بخلاف ما ذكر كوقوعه من الأدنى إلى الأعلى أو من

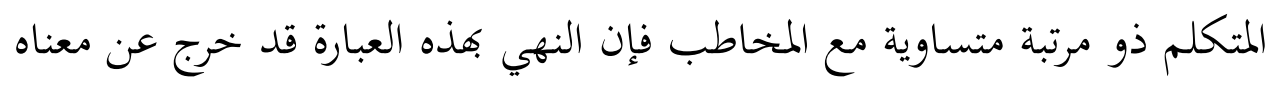

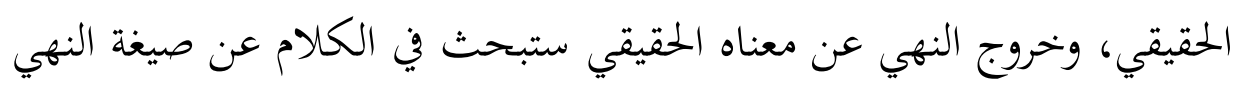

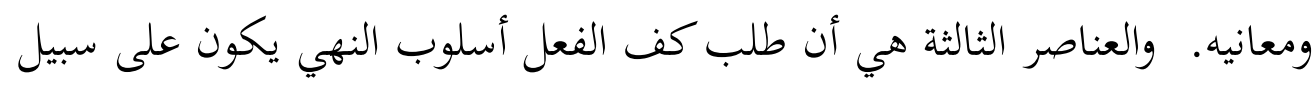

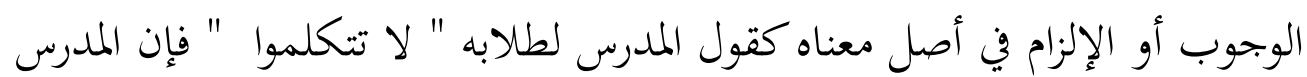

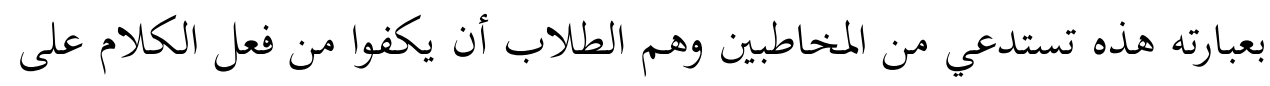

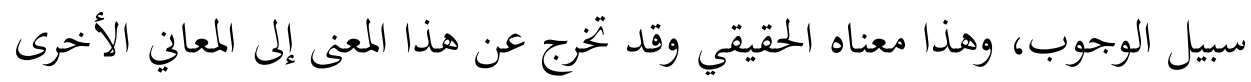
التي سيأتي بيانه. 
إن أحكام النهي في علم المعاني ترتبط ارتباطا وثيقا بنفس موضوع هذا العلم وهو كما ذكر اكتشاف معاني اللفظ العربي من حيث إفادة معاني الثواني التي هي الأغراض المقصودة للمتكلم من جعل الكالام مشتملا على تلك اللطائف

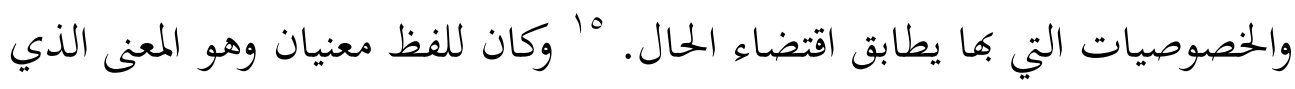
يفهم من اللفظ بحسب التركيب وهو ما يسمى بالمعاني الأول والمعني الذي يصدر من مقتضيات الأول أوالأغراض التي يساق لها الكالام ويسمى هذا المعنى المعنى الثواني وذلك كقولك إن محمدا طالب ، فهذه العبارة كانت لها معنيان فالمعنى الأول هو الحضور المؤكد والمعنى الثاني هو رد الإنكار ورد الشك بالتوكيد. بإ إذا يفهم من بيان السابق أن أحكام النهي في العلم المعاني تتعلق باكتشاف أسرار المعاني التي تتضمن بها أسلوب النهي.

فالنهي في معناه الحقيقي هو طلب كف الفعل على سبيل الإستعلاء واللزوم، وهذا المعنى قد تتعدل إلى معاني مختلفة حسب مقضيات الأحوال بدلالة القرينه التي تدل على عدولها. فالنهي إذا كان يصدر من الأعلى إلى الأدنى فيحكم بأنه النهي بمعنى الحقيقي، أما إذا كان النهي يصدر من الأدنى إلى الأعلى فيحكم

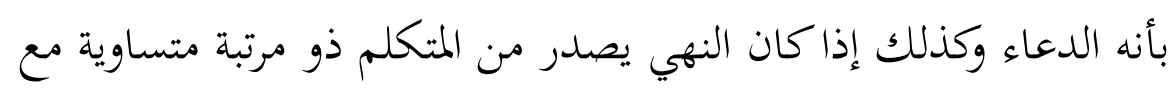

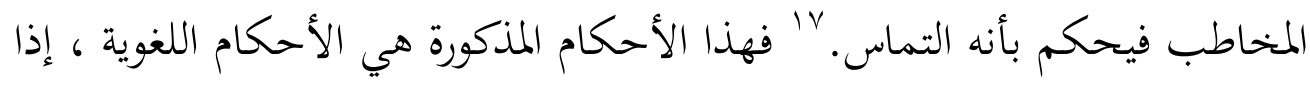
فلزوم كف الفعل في النهي عند علماء المعاني هو لزوم لغوي هذا بخلاف ما أثبته الأصوليون التي تتعلق بأحكام الشرعية.

\footnotetext{
"' ". أممد الهاشمي، المصدر السابق، ص: 46

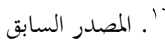

"' ". عبد العزيز عتيق، المصدر السابق، ص: 80
} 
للنهي صيغة أصلية واحدة ، وهي كل فعل مضارع بحزوم بلا الناهية، كقوله تعالى ( ولا تقربوا الزنا ) وقوله سبحانه ( ولا تنكحوا المشركات حتى يؤمن ). تلك الصيغة تدل على طلب الكف عن الفعل بأصل وضعها. أصل معنى صيغة النهي عند علماء المعاني طلب كف الفعل من الأعلى إلى الأدنى على سبيل اللزوم، وهذا هو معناه الحقيقي. ^ا وقد تعدل هذا المعنى إلى معاني متعددة تستفاد من سياق الكام وقرائن الأحوال. 19 وهذه المعاني كما تلي شرحه : أ. معنى الدعاء، كقوله تعالى ( ربنا لا تؤاخذنا إن نسينا أو أخطأنا ). ب.والالتماس كقولك لمن يساويك " أيها الأخ لا تتوان " ج. والإرشاد ، كقوله تعالى ( لا تسألوا عن أشياء إن تبد لكم تسؤكم ) د. والدوام، كقوله تعالى ( ولا تحسبن الله غافلا عما يفعل الظالمون ) هـ وبيان العاقبة، نحو قوله تعالى ( ولا تحسبن الذين قتلوا في سبيل الله أمواتا بل

$$
\text { (أحياء }
$$

و. والتيئيس، كقوله تعالى ( لا تعتذروا قد كفرتم بعد إيمانكم )

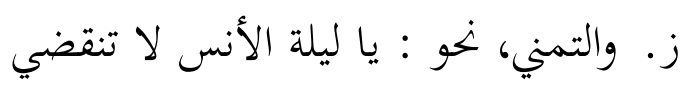

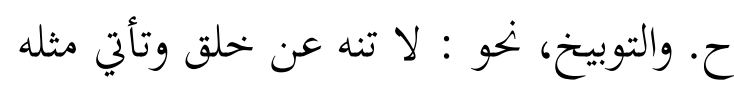
ط. والإئتناس، مثل : لا تخزن إن الله معنا ي. والتحقير، كقوله : لا تطلب المحد إن البحد سلمه صعب - وعش مستريحا ناعم

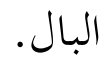


وهذه المعاني المذكورة من أنواع معاني النهي التي قد خرجت من أصل معناه، وتعرف هذه المعاني من سياق الكالام وقرائن الأحوال. وهات مثلا معنى النهي بمعنى التوبيخ في قولك: لا تنه عن خلق وتأتي مثله، فالنهي في هذه العبارة ليس معناه الحقيقي لطلب كف الفعل على سبيل الاستعلاء واللزوم بل كان الغرض من المتكلم توبيخ فعل المخاطب الذي يخالف بين الفعل والكالام. وكذالك معنى النهي بمعنى الائتناس في قوله: لا تحزن إن الله معنا، فليس غرض المتكلم بكامه هذا لمنع المخاطب من التحزن على سبيل الاستعلاء واللزوم بل المراد هنا تسلية المخاطب وائتناسه من الحزن المستقر في نفسه.

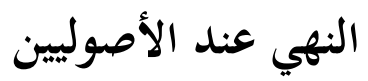

والمراد من كلمة الأصول في هذا البحث هو أصول الفقه لا أصول الدين أو غيره. وأصول الفقه فرع من فروع العلوم الشرعية الإسلامية الذي نشأ متجانبا مع علم الفقه. وأول من أسس هذا العلم هو الإمام العالم المحتهد محمد بن إدريس

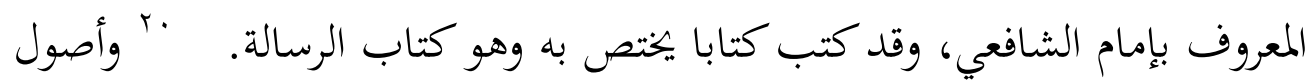
الفقه هو إدراك القواعد التي يتوصل بها إلى الاستنباط الأحكام الشرعية الفرعية عن أدلتها التفصيلية، 'ب أو بحموعة القواعد والبحوث التي يتوصل بها إلى استفادة

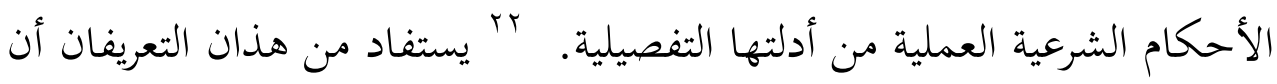

$$
\begin{aligned}
& \text { "' ". عبد الوهاب خلاف، المصدر السابق، ص: } 17
\end{aligned}
$$

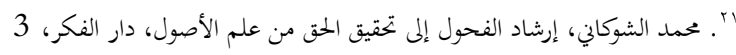

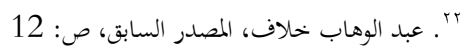


علم أصول الفقه هو علم الذي يختص بالقواعد التي يستنبط منها الأحكام الشرعية العملية.

وأما موضوع البحث في علم أصول الفقه فهو الدليل الشرعي الكلي من

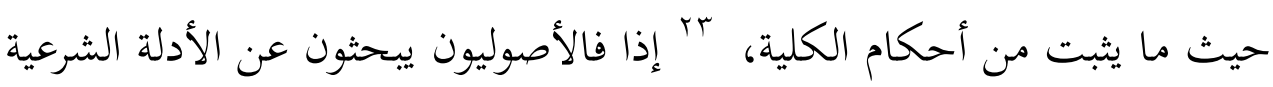
ليتوصلوا إلى نوع الحكم الكلي الذي يدل عليه مستعينا باستقراء الأساليب العربية والاستعمالات الشرعية. والغاية المقصودة منها فهي تطبيق قواعده ونظرياته على الأدلة التفصيلية ليتوصل إلى الأحكام الشرعية التي تدل عليها، وذلك مثل قوله تعالى " ولا تقربوا الزنا إنه كان فاحشة وساء سبيلا " فدلالة النهي في هذه الآية للتحريم، وهذا يعرف من الدلالة الشرعية الموجودة بعده وهي أن الله تعالى يذم هذا الفعل في قوله " إنه كان فاحشة وساء سبيلا " والفعل المذموم يدل على حرمته. البحث عن النهي من المباحث التي اشتغلت بها الأصوليون من أجل توصلهم إلى نوع الحكم الكلي الذي يتضمنه النصوص الشرعية التي تأتي بأسلوب النهي. ومفهوم النهي عند الأصوليون لا يختلف بعيدا عما عرفه به علماء المعاني وهو استدعاء ترك الفعل بالقول ممن هو دونه أو القول الإنشائي الدال على طلب كف عن فعل على جهة الاستعلاء. عُr وكان وجه الخلاف بينهما يرجع إلى الغاية المنشودة بين هذين العلمين، وغاية علماء المعاني كما ذكر هو لمعرفة معاني النهي بين معاني الحقيقي وغيره، وكذالك من غايتهم بيان طريقة استخدام أسلوب النهي 
وفقا بمقتضيات الأحوال حتى صار المتكلم فصيحا في أداء كلامهم لا سيما في

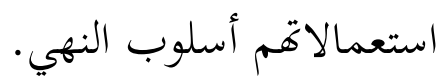

فالأصوليون يبحثون عن النهي مستعينا باستقراء الأساليب العربية كما

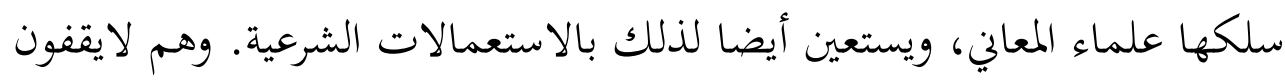

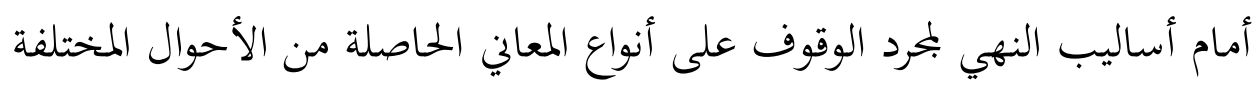

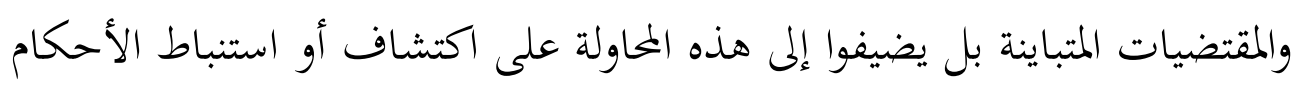
الكلية من خلال النصوص تحمل أساليب النهي.

وذكر الأصوليين أن صيغة النهي الأصلي هي الفعل المضارع المقرون بلا

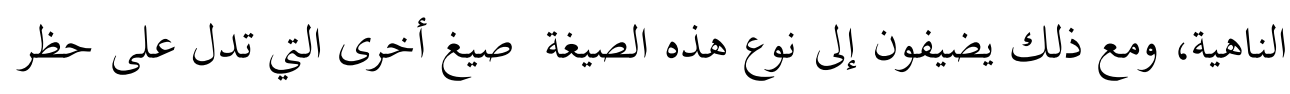

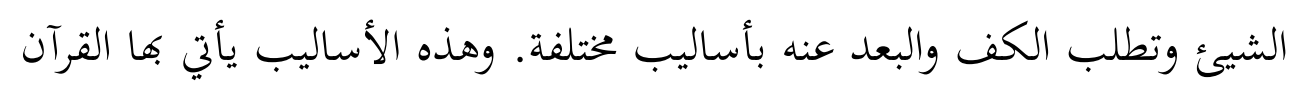

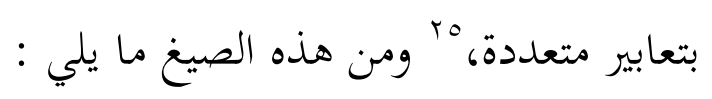

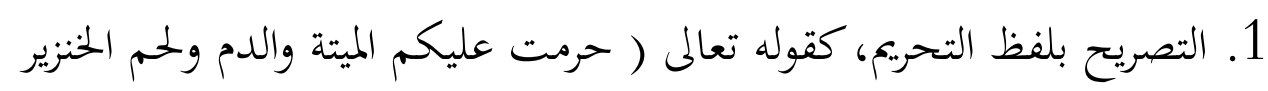
2. نفي الحل، كقوله تعالى ( يايها الذين آمنوا لا يحل لكم أن ترثوا النساء كرها ) 3. صيغة الأمر بالكف والترك، كقوله تعالى ( وذروا ظاهر الإثم وباطنه )

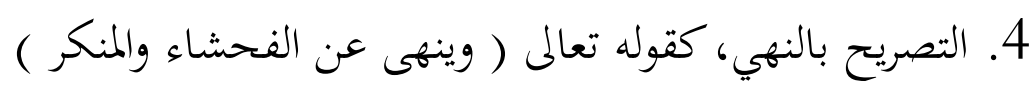

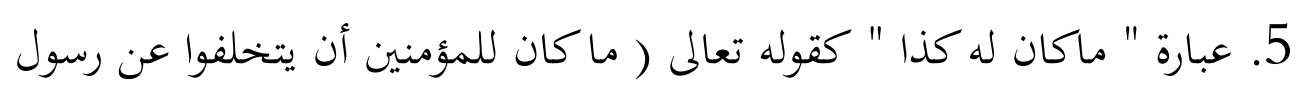
الله ). (مبارة 
6. ذكر عقاب مرتكب الفعل في الآخرة، كقوله تعالى ( ومن يقتل مؤمنا متعمدا فجزائه جهنم ).

7. الوعيد على الفعل، كقوله تعالى لمن يعامل بالربا ( فأذنوا بحرب من الله ورسوله )

8. ذم الفاعل أو لعنه أو وصف الفعل بأنه من الكبائر أو من فساد وتزيين

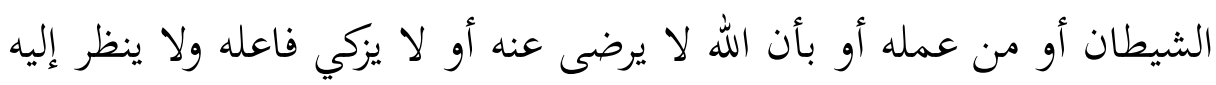
مما يفيد الزجر، كقوله تعالى ( ولا يرضى لعباده الكفر ).

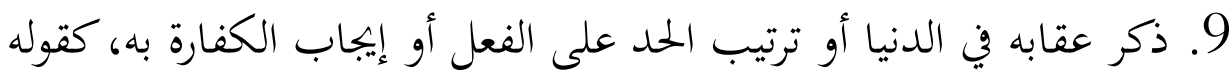

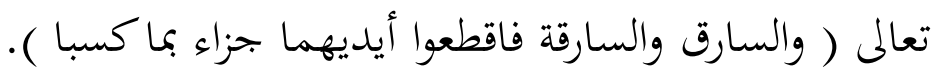

لقد سلك الأصوليولون في بيان أحوال النهي مسالك متعددة، بات وعبروا عن مرادهم ب عبارات مختلفة، ولكن جميعها تنحصر في الأحوال التالية: الحالة الأولى : أن يأتي النهي مطلقا أي مطلقا عن القرائن الدالة على أن

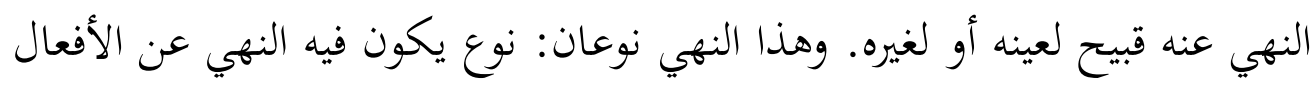

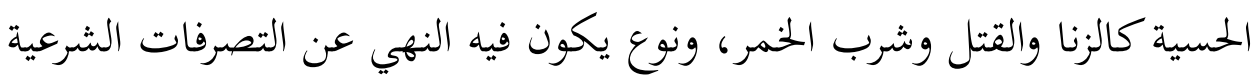

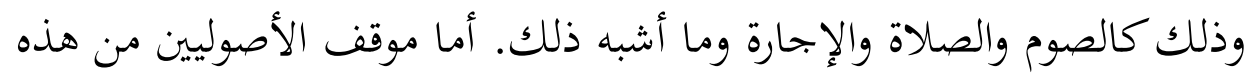

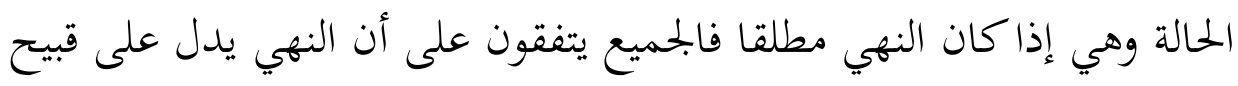

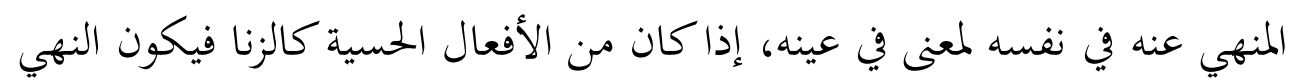
دالا على الفساد المرادف للبطلان ، مالم يدل دليل على أن النهي لوصفه أو المحاور 


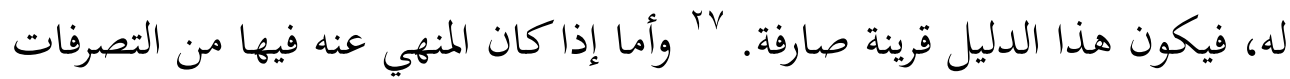
الشرعية، فإِهم اختلفوا في دلالته على الفساد والبطلان على الأقوال: 1. أن النهي المطلق عن الأفعال الشرعية يدل على بطلاهها، ويثبت القبح في عين

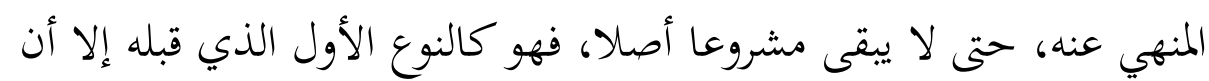
يقوم دليل يصرفه عن هذه الحقيقة. وهذا هو قول أكثر أصحاب الشافعي، وهو الظاهر من هذهبه.

2. أنه لا يدل على ذلك ، وهذا هو قول الحنفية، وإليه ذهب المقققون من أصحاب الشافعي كالغزالي وأبي بكر القفال. 3. أنه يدل على الفساد في العبادات دون المعاملات، وعز الشوكاني هذا القول في

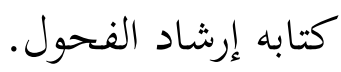
تم القائلون بالبطلان اختلفوا فيما بينهم هل يقتضي البطلان لغة أو شرعا، والراجح أنه يقتضيه شرعا لا لغة. ثم القائلون إنه لا يقتضي البطلان مطلقا اختلفوا

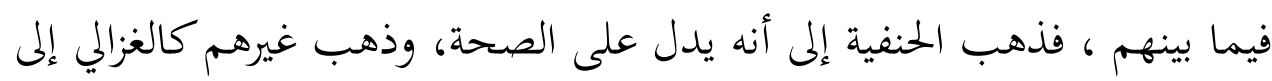

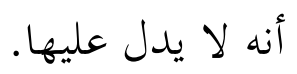

الحالة الثانية: أن يكون النهي راجعا لذات الفعل أو لجزئه، وذلك كالنهي عن بيع الحصاة فيما روى أبو هريرة رضي الله عنه أن النبي صلى الله عليه وسلم فهى عن بيع الحصاة، وبيع الحصاة كما ورد تفسيره في بعض الأحاديث هو أن يجعل 
نفس الرمي بيعا، فالنهي إذا إلى ذات الفعل. وموقف الأصوليين من هذه الحالة هي

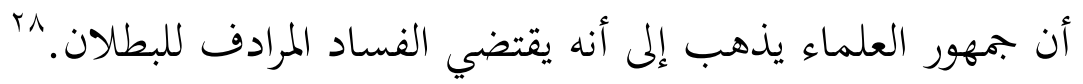

الحالة الثالثة: أن يكون النهي راجعا إلى وصف لازم للمنهي عنه دون

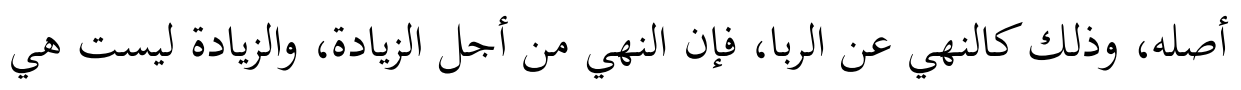

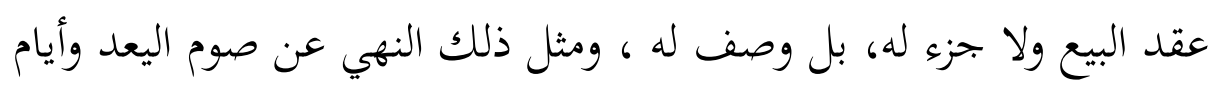

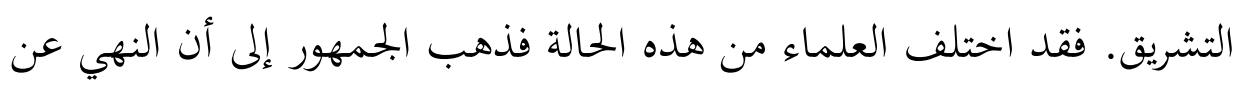

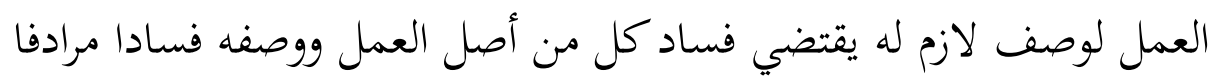

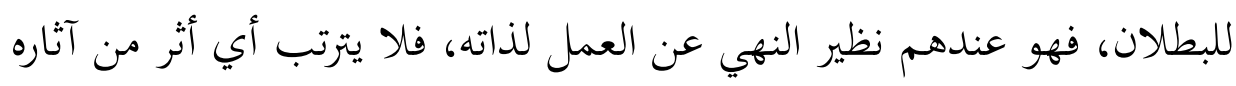

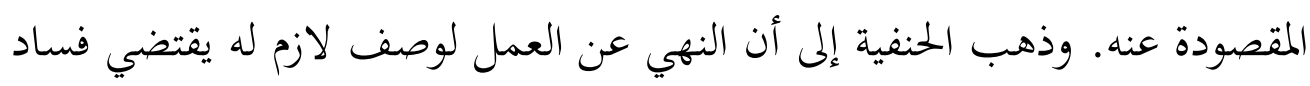

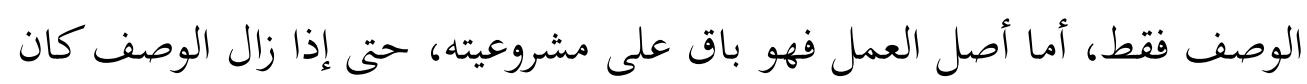

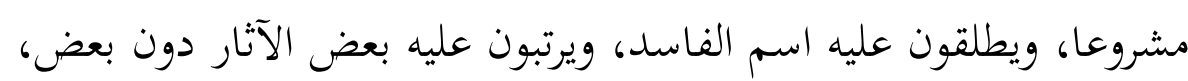
فالفاسد عندهم هنا غير باطل. الحالة الرابعة: أن يكون النهي عن العمل راجعا إلى وصف بحاور له، ينفك

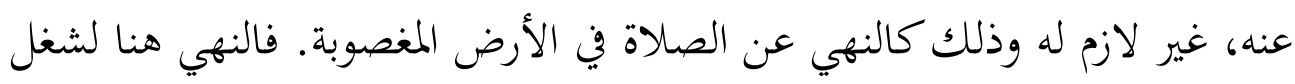

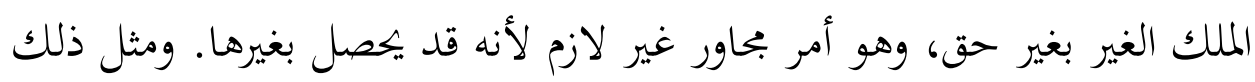

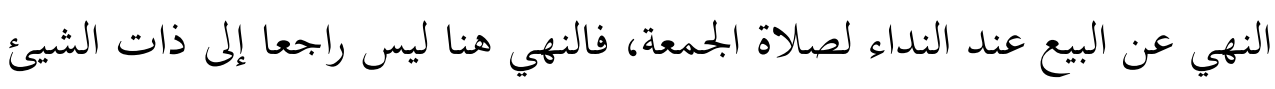

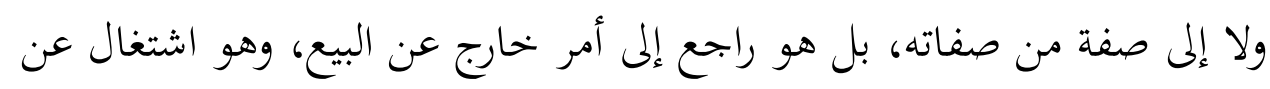

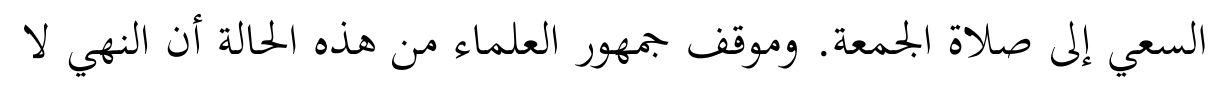

$$
\text { ^^^^". المصدر السابق، ص: } 248
$$


يقتضي بطالان العمل ولا فساده، بل يبقى صحيحا تترتب عليه آثاره المقصودة منه

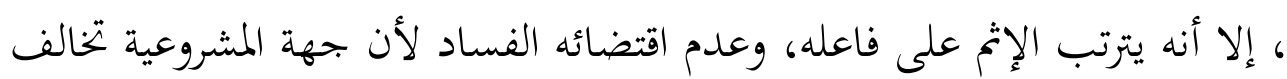
جهة النهي فلا تلازم بينهما.

\section{وجوه الاتفاق والاختلاف}

من العرض السابق - وهو مفهوم النهي لدى الأصوليين والبلاغيين - يمكن أن يستنتج خلاصة الاتفاق والاختلاف بين البلاغيين والأصوليين نخو ابحاهاهم بالبحوث عن النهي وهي كما تلي:

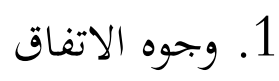

فوجوه الاتفاق عن بكوث النهي بين هذين العلمين كما يلي:

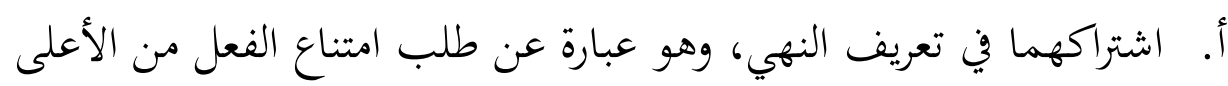
إلى الأدنى. من هذا الوجه يشترك بين البلاغيين والأصوليين في تحديد معنى النهي وإن كان هناك التعاريف المختلفة ولكن حقيقتها متقاربة. ب. الاشتراك في استعمال صيغة النهي وهي الفعل المضارع المقرون بلا الناهية، بيد أن الأصوليين يضيفون ويعدون من أنواع صيغ النهي الصيغ التي تدل معنى النهي وهي كالتصريح بلفظ التحريم وغيره.

ج. البلاغيون والأصوليون يتفقون في تقسيم النهي بين معانيه الحقيقية والبحازية. 2. وجوه الاختلاف أما الوجوه الاختلاف بينهما كما يلي: 


\section{أ. موضوع البحث}

اختلاف موضوع البحث بين هذين العلمين يترتب إلى اختلاف البلاغيين والأصوليين في بحثهما عن النهي. فكان موضوع البحث من علم البلاغة هو تأدية معنى الجليل واضحا بعبارة صحيحة فصيحة لما في النفس أثر خلاب مع ملاءمة للموطن الذي يقال فيه والأشخاص الذين يخاطبون. أو بعبارة أخرى أن علم البلاغة هو علم الذي يبحث عن طريقة استخدام اللغة فعالا حتى لا يقع بين المتكلم والمخاطب سوء الفهم في اتصالمما. فلبالاغيون يبحث عن النهي لأجل معرفة معاني النهي بين الحقيقي والجمازي وطريقة استخدامهما في الكام.

أما موضوع البحث في علم أصول الفقه فهو الدليل الشرعي الكلي من حيث ما يثبت من أحكام الكلية، إذا فالأصوليون يبحثون عن الأدلة الشرعية ليتوصلوا إلى نوع الحكم الكلي الذي يدل عليه مستعينا باستقراء الأساليب العربية والاستعمالات الشرعية. فالأصوليون يبحثون عن النهي مستعينا باستقراء الأساليب العربية كما سلكها علماء المعاني، ويستعين أيضا لذلك بالاستعمالات الشرعية. وهم لايقفون أمام أساليب النهي بلمرد الوقوف على أنواع المعاني الحاصلة من الأحوال المختلفة والمقتضيات المتباينة بل يضيفوا إلى هذه المحاولة على اكتشاف أو استنباط الأحكام الكلية من خلال النصوص تحمل أساليب النهي. ب. غاية البحث

تختلف بين البلاغيين والأصوليين في غاية البحث بينهما فغاية البلاغيين من بحث النهي استخراج الأحكام المتضمنة في صيغ النهي، فالبلاغيون يستخرجون منها الأحكام اللغوية التي تميز بين المعنى الحقيقي والمحازي. من خلال هذه المعاني 
يعرف كيف استخدام أسلوب النهي وفقا بمقتضى الحال وبأحوال المخاطبين. وغاية علماء المعاني كما ذكر هو لمعرفة معاني النهي بين معاني الحقيقي وغيره، وكذالك من غايتهم بيان طريقة استخدام أسلوب النهي وفقا بمقتضيات الأحوال حتى صار المتكلم فصيحا في أداء كلامهم لا سيما في استعمالاهم أسلوب النهي. أما الأصوليون فأغراضهم البحوث عن النهي لغرض استخراج الأحكام الشرعية الكلية التي تتفرع منها الأحكام الشرعية الجزئية، فيستخرجون من خلال بحوثهم عن النهي الأحكام الشرعية الكلية كالنهي يدل على البطلان أو الفاسد إذا كان النهي مطلقا عن القرائن الدالة على أن النهي عنه قبيح لعينه أو لغيره، أو لا يدل على البطلان إذا كان النهي عن العمل راجعا إلى وصف بحاور له، ينفك عنه، غير لازم له. فغاية من هذا البحث هي تطبيق قواعده ونظرياته على الأدلة التفصيلية ليتوصل إلى الأحكام الشرعية التي تدل عليها.

\section{الخحاتمة}

قد اشترك البلاغيون والأصوليون في بحثهم عن النهي في اللغة العربية، ثم إن غايتهم تختلف بينهما اختلافا ترجع مصادرها إلى اختلاف الموضوع بين هذين العلمين. فالبلاغيون يبحث عنه لأجل استخراج الأحكام اللغوية المتضمنة في تلك النصوص التي تحتمل فيها صيغ النهي، فيستنتج من بحوثهم أن لأسلوب النهي معنيين إما أن تكون حقيقية وإما غير حقيقية أو بحازية. وينطلق من نتائج بحثهم هذه تعرف كيف تستخدم هذه الصيغة النهيية في لغة الإتصال حتى تكون المواصلة بين المتكلم والمخاطب بليغا وفصيحا. 
أما الأصوليون فليس من شأفم أن يبحثوا عن النهي لأغراض استخراج

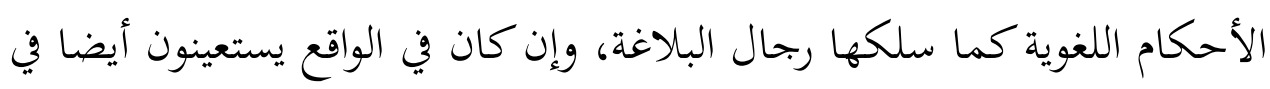

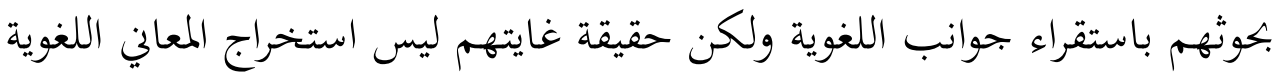

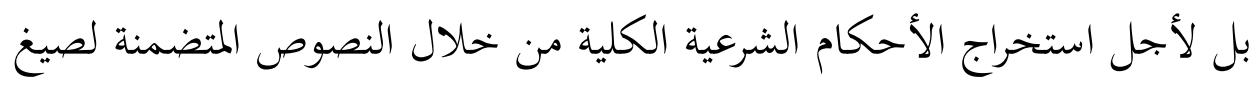

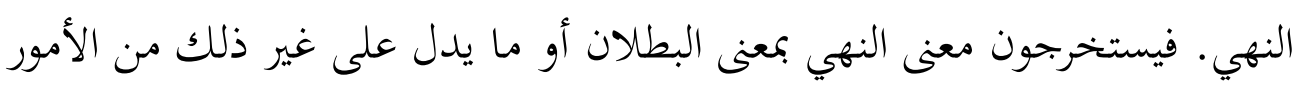
التي تتعلق بالأحكام الشرعية الكلية. 


\section{Daftar Kepustakaan}

al-Khan, Musthafa Sa'id, Atsar al-Ikhtilaf Fi al-Qawaid, al-Ushuliyyah Fi Ikhtilaf al-Fuqaha', Beirut, Muassasah al-Risalah, 1998

Al-Khalaf, Abdul Wahab, Ilmu Ushul al-Fiqh, t.k, Dar al-Ilm, 1978

Al-Hasyimi, Ahmad, Jawahir al-Balaghah Fi al-Ma'ani wa al-Bayan wa al-Badi', Indonesia, Maktabah Dar Ihya Kutub al-Arabiyah, t.th

'Akawi, Fawwal In'am, al-Mu’jam al-Mufasshol Fi Ulum al-Balaghoh al-Badi' alBayan al-Ma'ani, Beirut, Dar Kutub al-Arabi, 1971

'Atiq, Abdul Aziz, Ilm al-Ma'ani al-Bayan al-Ma'ani, Beirut, Dar al-Nahdhah alArabiyah, t.th

al-Syaukani, Muhammad, Irsyad al-Fahul Ila Tahqiq al-Haq Min Ilm al-Ushul, t.k, Dar al-Fikr, t.t

H.D. Hidayat, al-Balaghah Li al-Jami' wa al-Syawahid Min Kalam al-Badi', Semarang, PT. Toha Putra, t.t

Tamam Hasan, al-Ushul, Dirasah Epistemologiyah Li Ushul al-Fikri al-Lughawi alArabi, al-Maghrib, Dar al-Tsaqafah, 1991

Zuhaili, Wahbah, Ushul al-Figh al-Islamiy, Damsyiq, Dar al-Fikr, t.t 